\title{
Modular Diversification of the Locomotor System in Damselfishes (Pomacentridae)
}

\author{
Rosalía Aguilar-Medrano, ${ }^{1,2 \star}$ Bruno Frédérich, $^{3}$ and Paul H. Barber ${ }^{1}$ \\ ${ }^{1}$ Department of Ecology and Evolutionary Biology, University of California, 621 Charles E. Young Dr. South, \\ Los Angeles, California, 90095, USA \\ ${ }^{2}$ Instituto De Ecología Aplicada, Universidad Autónoma De Tamaulipas, 356 División Del Golfo, Col. Libertad, \\ Ciudad Victoria, Tamaulipas, 87029, México \\ ${ }^{3}$ Laboratoire De Morphologie Fonctionnelle Et Evolutive, AFFISH Research Center, Université De Liège, \\ Liège, Belgium
}

\begin{abstract}
As fish move and interact with their aquatic environment by swimming, small morphological variations of the locomotor system can have profound implications on fitness. Damselfishes (Pomacentridae) have inhabited coral reef ecosystems for more than 50 million years. As such, habitat preferences and behavior could significantly constrain the morphology and evolvability of the locomotor system. To test this hypothesis, we used phylogenetic comparative methods on morphometric, ecological and behavioral data. While body elongation represented the primary source of variation in the locomotor system of damselfishes, results also showed a diverse suite of morphological combinations between extreme morphologies. Results show clear associations between behavior, habitat preferences, and morphology, suggesting ecological constraints on shape diversification of the locomotor system. In addition, results indicate that the three modules of the locomotor system are weakly correlated, resulting in versatile and independent characters. These results suggest that Pomacentridae is shape may result from the interaction between (1) integrated parts of morphological variation that maintain overall swimming ability and (2) relatively independent parts of the morphology that facilitate adaptation and diversification. J. Morphol. 000:000-000, 2016. (C) 2016 Wiley Periodicals, Inc.
\end{abstract}

KEY WORDS: modularity; integration; locomotion; geometric morphometrics; reef fish; ecomorphology; evolutionary morphology

\section{INTRODUCTION}

Considerable morpho-functional diversity in fishes is seen in the structures of the locomotor system because density-related inertial forces in aquatic systems have high impacts on swimming performance (Videler, 1993). Because swimming is the primary way that fish interact and move through their environment (Fulton, 2010), swimming performance is a major determinant of (1) individual survival, (2) growth, and (3) lifetime reproductive fitness (Webb, 1994; Plaut, 2001; Blake, 2004). As such, small variations in swimming abilities within and among species can have profound impacts on these three key life history parameters (Koch and Wieser, 1983; Boisclair and Sirois, 1993), making swimming performance a primary target for natural selection (Huey and Stevenson, 1979; Hertz et al., 1988).

Many studies have examined the role of body and fin shape on swimming performance in teleosts (Webb, 1982; Bushnell and Moore, 1991; Lighthill, 1993; Gibb et al., 1994; Gibb et al., 1999; Drucker and Lauder, 2001, 2005; Wainwright et al., 2002; Fulton et al., 2005; Fulton, 2007; Standen, 2008; Aguilar-Medrano et al., 2013). Fewer studies have examined the coordination of the locomotor and feeding system (Rice and Westneat, 2006; Higham, 2007), and only one study has explicitly tested the correlated evolution of teleost feeding and locomotor systems within a single clade (i.e., labrids; Collar et al., 2008). As such, it is unclear how morphological variation within a single taxonomic group may be correlated to niche partitioning via swimming performance during evolution.

Pomacentridae (damselfishes) is a speciose family of 394 species of marine fish (Eschmeyer, 2014) that has inhabited reef ecosystems for more than 50 million years (Bellwood, 1996; Bellwood and Sorbini, 1996). The vast majority of damselfish inhabit tropical coral reefs, although some species live in rocky reefs or kelp forests in temperate coastal waters. Due to their wide range of

\footnotetext{
Additional Supporting Information may be found in the online version of this article.

*Correspondence to: Rosalía Aguilar Medrano, Department of Ecology and Evolutionary Biology, University of California, 621 Charles E. Young Dr. South, Los Angeles, CA 90095.

E-mail: liabiol@gmail.com.
}

Received 30 September 2015; Revised 24 January 2016; Accepted 28 January 2016.

Published online 00 Month 2016 in Wiley Online Library (wileyonlinelibrary.com). DOI 10.1002/jmor.20523 
behaviors and habitat preferences in structurally complex environments, damselfishes are an excellent model to test the role of the locomotor system shape on niche partitioning and diversification.

The majority of ecomorphological studies on damselfishes have focused on the relationship between morphology and diet (Emery, 1973; Frédérich et al., 2008; Cooper and Westneat, 2009; Aguilar-Medrano et al., 2011; Frédérich et al., 2013). Only two key studies analyzed the ecomorphological variation of swimming performance (Fulton, 2007; AguilarMedrano et al., 2013). In this study, we analyze the morphology of the locomotor system of damselfishes from the perspective of modularity. Modularity refers to semiautonomous units (modules) that comprise higher organisms (Simon, 1962; Wagner and Altenberg, 1996). Modules are assemblages of parts that are integrated internally by strong interactions, but are relatively independent of one another by few or weak interactions (Wagner and Altenberg, 1996; Klingenberg, 2005). We focus on modules because of their possible role as "building blocks" of phenotypic adaptation (Wagner, 1995).

Functional modularity is an important determinant of evolutionary diversification because it provides a link between the modular structure of morphological traits and selection on performance in organismal functions (Klingenberg, 2008). Hence, in an evolutionary context, a module is a set of morphological characters that (1) collectively serve a common functional role, (2) are tightly integrated, and (3) are relatively independent from other modules (Mitteroecker and Bookstein, 2007).

Here, we focus on three morphological modules that play different roles in swimming fitness: module 1, cephalic region, associated with drag reduction and lift forces (Bushnell and Moore, 1991; Lighthill, 1993; Larouche et al., 2015); module 2, trunk, dorsal, pelvic, and anal fins, associated with stability and thrust (Harris, 1938; Drucker and Lauder, 2001, 2005; Fulton, 2007; Standen, 2008); and module 3, caudal peduncle, associated with acceleration and thrust (Webb, 1982; Gibb et al., 1999; Fig. 1). We study the variation along these morpho-functional axes in an evolutionary context, focusing on the relationship between habitat preferences and behavior to address three questions: (1) how the morphological modules vary within Pomacentridae, (2) do these morpho-functional modules evolve individually or as an integrated system?, and (3) do behavior and habitat preferences impact the morphological variation of each module?

\section{MATERIAL AND METHODS Morphological Data}

We conducted morphometric analyses on 739 lateral-view photographs of adult damselfish, representing 205 species from the time-calibrated phylogeny of Frédérich et al. (2013). These samples represent 27 of 29 genera; however, the two missing genera, Amblypomacentrus and Altrichthys, only contain two

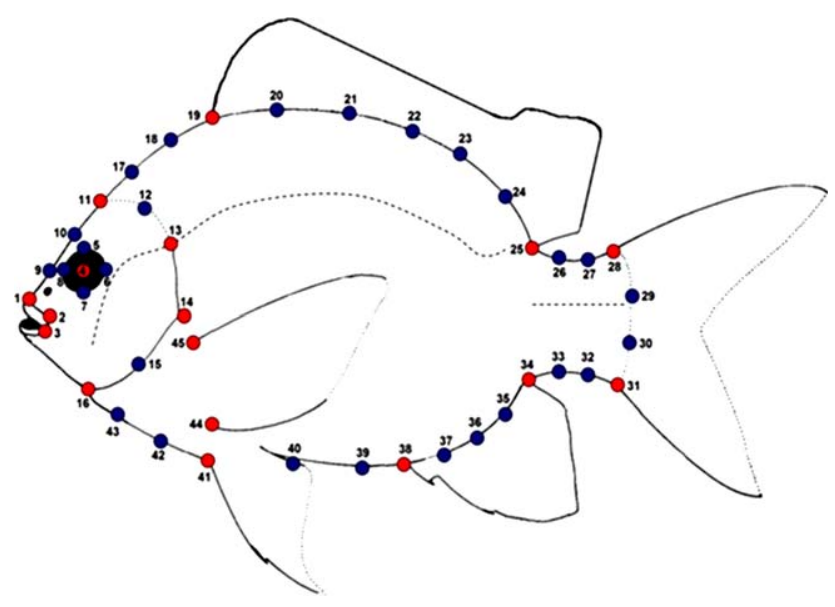

Fig. 1. Landmaks (LMs, red dots) and semilandmarks (SLMs, blue dots) used to analyze the locomotor system of damselfishes. A: module 1, cephalic region (CR; LMs \& SLMs 1-18); module 2, trunk (LMs \& SLMs 19 to 25 and 34 to 45); module 3, caudal peduncle (CP; LMs \& SLMs 26 to 33 ).

species, are very similar in shape to Pomacentrus and Chrysiptera (Allen, 1991) and are recently diverged from these genera (Frédérich et al., 2013). As such, the absence of these genera should not impact the results of the study. Photographs were largely obtained directly from accessioned museum specimens, with additional photographs from online resources such as MorphBank (www.morphbank.net), FishBase (Froese and Pauly, 2014) and John E. Randall's Fish Photos (pbs.bishopmuseum.org/images/JER). The complete list of species included in this study, their sources and accession numbers are available as supplementary online material 1 .

We conducted landmark (LM)-based geometric morphometric analyses (Bookstein, 1991; Rohlf and Marcus, 1993; Rohlf, 1999; Zelditch et al., 2004), recording $x, y$ coordinates of LMs and semilandmarks (SLMs) using TpsDig, version 2.17 (Rohlf, 2014). SLMs were identified using a slider file made in TpsUtil (Rohlf, 2014). First, we studied the whole body shape variation using a configuration made of $17 \mathrm{LMs}$ and 28 SLMs. Then, the overall body was divided into three modules based on functional analyzes: module 1: cephalic region delimited by eight LMs and 10 SLMs; module 2: trunk delimited by seven LMs and 14 SLMs, and module 3: caudal peduncle delimited by two LMs and six SLMs (Fig. 1). For every data set, superimposition of LM configurations was achieved using Generalized Procrustes Analysis (Rohlf and Slice, 1990). We calculated Partial Warp scores, and we performed a Principal Components Analyses (PCA) of shape variables (also called Relative Warps analysis, RWs) using TpsRelw, version 1.54 (Rohlf, 2014). PCA was used to find hypothetical variables (components) that account for much of the variance in the morphological data (Davis, 1986). Principal components scores were used as descriptors of shape variation (Bookstein, 1991; Rohlf, 1993). Deformation grids using the thin-plate spline algorithm were used to visualize the patterns of shape variations along PC axes (Bookstein, 1991; Rohlf, 1993).

We tested the relevance of modules defined a priori based on functional considerations using Escoufier's RV-coefficient and the multi-set RV-coefficient (Klingenberg, 2009; Larouche et al., 2015). RV-coefficient analysis is a robust method to test whether a priori defined modules fit observed covariance matrices better than a distribution of randomly generated modules of equivalent size and number (Goswami and Polly, 2010a). The RV coefficient is analogous to a correlation coefficient, but instead of measuring the association between two individual variables, it measures the association between two sets of variables. It ranges from zero to one, with zero representing a case 
of perfect modularity, in which there is no covariance between the sets. Thus a lower value in a priori defined modules than in randomly generated modules indicate that none of the randomly generated modules are better than the a priori defined modules. The validation of this modular configuration was done using the function compare modular partitions in geomorph V.20 (Adams et al., 2014) for R.

\section{Allometric Variation}

We tested the relationship between shape and size across species using a multivariate regression of shape variables (RWs) onto the centroid size (CS) (Bookstein, 1991; Monteiro, 1999) using TpsRegr, version 1.41 (Rohlf, 2014).

\section{Ecological and Behavioral Diversity}

We collected ecological and behavioral data from published literature for each species, focusing on four major characters. First, we recorded wave exposure, binning this variable into: (1) zero to low, (2) moderate, and (3) high wave exposure. Second, we characterized position in the water column in relation to the substratum as: (1) on the substratum (e.g., territorials)/ close to the substratum, (2) midwater/close to the surface, or (3) both. Finally we characterized behavior as: (1) perennial territorials, solitary, or couples, (2) schooling non-perennial territorials, or (3) solitary, pairs, or small groups non-perennial territorials (Supporting Information 1).

\section{Phylogenetic Comparative Methods}

We examined the evolution of morphological and ecological traits using the time calibrated phylogeny of Frédérich et al. (2013). We hypothesized that evolution should favor integration within the swimming system. So, we used a phylogenetic generalized least square method (PGLS) that incorporated Brownian motion (BM) to test for a correlation between the three functional modules.

To test for a correlation between ecology and morphology, we used PGLS methods that incorporated two models of trait evolution, including BM, in which disparity increases as a function of time (Harmon et al., 2003), and the Ornstein-Uhlenbeck (OU) model that incorporates one or more optimum trait value $\theta_{n}$ and strength of selection $\alpha$ (Beaulieu et al., 2012). In other words, BM model is a completely stochastic model, while the OU-model incorporates both stochastic and stabilizing components (Butler and King, 2004). To identify the pattern of morphological diversification, we compared the fit of a BM-model and OU-model for each one of the three ecological variables: (a) wave exposure; (b) position in the water column in relation to the substratum; and (c) behavior. If these ecological variables shaped the evolution of damselfish morphology, we expected that the OU-model would show better fit than the BM model. To evaluate the best model for our data, we compared the fit of both models using Akaike's information criterion (AIC), which considers the trade-off between the fit and the complexity of the model (Akaike, 1973).

For PGLS analysis, we used packages in the $\mathrm{R}$ environment version 3.0.3 (The $\mathrm{R}$ Foundation for Statistical Computing 2014): NLME (Pinheiro et al., 2014), GEIGER (Harmon et al., 2008), APE (Paradis et al., 2004), and CAPER (Orme et al., 2011).

\section{RESULTS}

\section{Main Axes of Morphological Variation}

For each module, we considered the PCs that explained at least $70 \%$ of the shape variation (Cangelosi and Goriely, 2007). For the cephalic region, four PCs accounted for $71 \%$ of shape variation $(\mathrm{PC} 1=30 \%, \mathrm{PC} 2=22 \%, \mathrm{PC} 3=11 \%, \mathrm{PC} 4=8 \%)$. In the trunk, three PCs accounted for $75 \%$ of the shape variation $(\mathrm{PC} 1=48 \%, \mathrm{PC} 2=17 \%, \mathrm{PC} 3=10)$. The caudal peduncle was the least complex module with two PCs accounting for $81 \%$ of shape variation $(\mathrm{PC} 1=68 \%, \mathrm{PC} 2=13 \%)$. For each module, the first axis of shape variation (PC1) was related to an elongation along the rostro-caudal axis of the body. For analyses of the whole body, the first four PCs accounted for $71 \%$ of the total variation $(\mathrm{PC} 1=41 \%$; $\mathrm{PC} 2=12 \% ; \quad \mathrm{PC} 3=10 \% ; \quad \mathrm{PC} 4=8 \% ; \quad$ Supporting Information 2).

Within the cephalic region (module 1) PC1 shows that species with horizontally lengthened cephalic profiles, typically have a snout at the same height or higher than the eyes, big eyes, an inferior region of the cephalic profile that is elongated downwards and backwards, a supraoccipital crest (SLMs 17 and 18) that is angled backwards and a more angular opercular margin (e.g., Azurina and Lepidozygus; Fig. 2B, PC1-). Conversely, species with horizontally short and vertically long cephalic profiles present the opposite character states (e.g., Dascyllus; Fig. 2A, PC1+). The second axis of variation shows that in species with big eyes close to the snout, the frontal area of the cephalic region is biggest and an elongated supraoccipital crest (SLMs 17 and 18; e.g., Azurina and some Chromis species; Fig. 2A,B, PC2+). In contrast, species with smaller eyes located below the snout present the opposite character states (e.g., Amphiprion; Fig. 2A, PC2-). The third axis of variation shows that in species with big eyes close to the snout, the frontal area is higher, producing a more rounded cephalic profile (e.g., some Pomacentrus, Chrysiptera Chromis, and Neopomacentrus species; Fig. 2C, PC3-), while species with smaller eyes located below the snout present the opposite character (e.g., some Abudefduf and Microspathodon species; Figs. 2C and 3D, PC3+). Finally, PC4 segregates species with big eyes and almost round cephalic profiles (e.g., some Chromis, Dascyllus, and Pomachromis species; Figs. 2C and 3D, $\mathrm{PC} 4+$ ) from medium sized eyes with and deepnarrow cephalic profiles (e.g., some Abudefduf and Lepidozygus species; Figs. 2C and 3D, PC4-).

The first axis of variation of the trunk (module 2 ) is related to an elongated profile of the trunk region resulting from a dorsal/ventral compression of the trunk, with greater compression in the center and anterior edges and less in the posterior. This morphology is associated with an elongated base of the pectoral fin, which is positioned anterior to the pelvic fin and the origin of the dorsal fin (e.g., some Lepidozygus and Azurina species; Fig. 3B, PC1+). The opposite morphology, shorter profile of the trunk region, is associated with the PC1- axis (e.g., Dascyllus; Fig. 3A, PC1-). The second axis of variation shows that in species with pectoral fins positioned anterior to the pelvic fin and origin of the dorsal fin, the dorsal and anal 


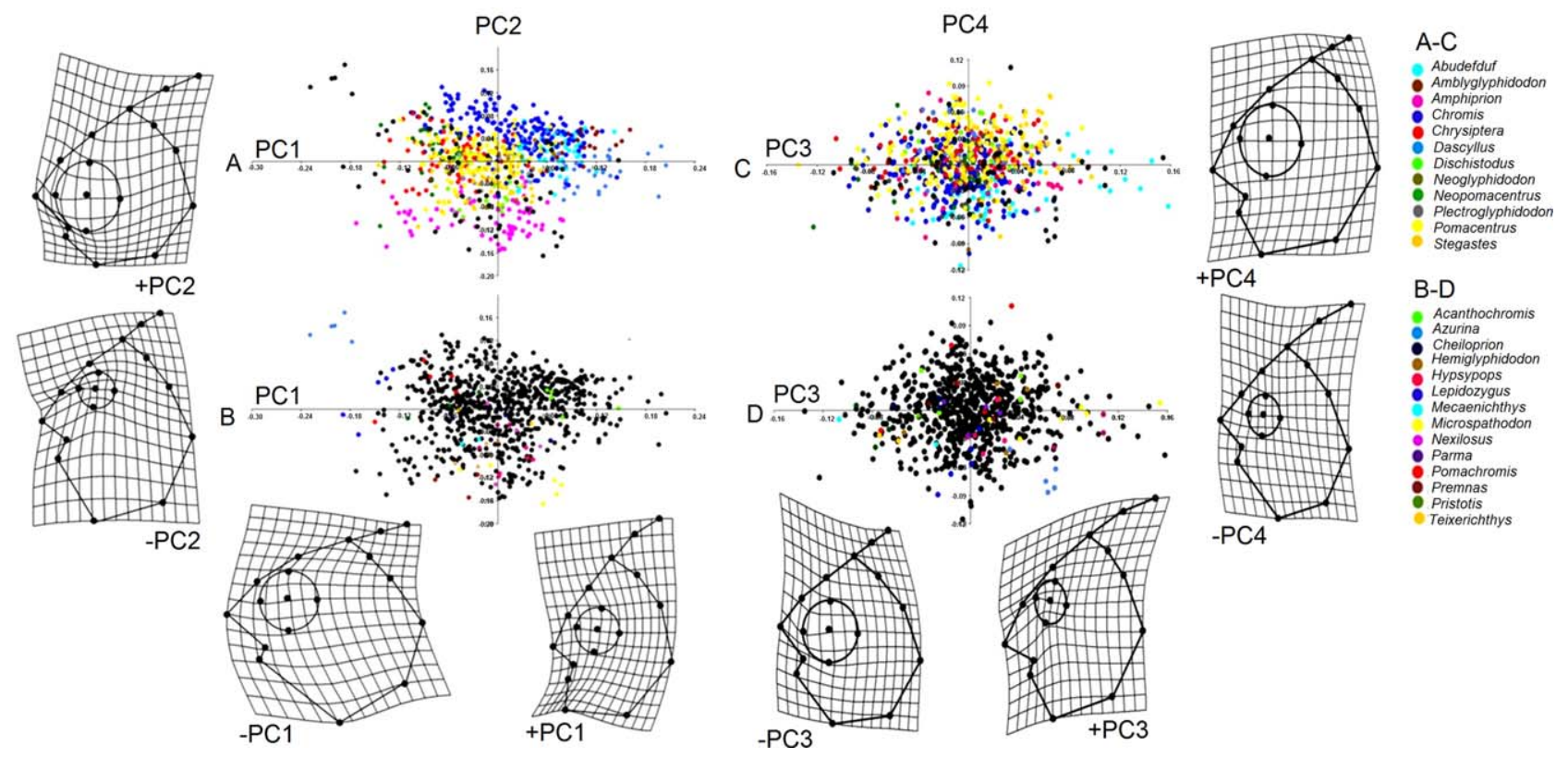

Fig. 2. Principal components analysis of the cephalic region. To highlight genera with few species the same graph is presented twice. Graph A includes all genera with more than five species while graph B only includes genera with less than five species. PC, principal component. Thin plate spline deformation grids represent the deformation of the most extreme specimen in each direction of the PC axes versus the grand mean.

fins are typically short resulting in a longer ventral distance between the pelvic and anal fin (e.g., some Abudefduf and Azurina species; Fig. 3A,B, PC2-). The opposite morphology, more elongated dorsal and anal fin, is associated with the PC2+ axis (e.g., some Amphiprion, Chromis, and Premnas species; Fig. 3A,B, PC2+). Finally, PC3 show that in species with pectoral fin positioned approximately at the same high of the pelvic fin, the anal fin is typically long and the dorsal fin short (e.g., some Lepidozygus species; Fig. 3D, PC3+). The opposite morphology, pectoral fins positioned anterior of the pelvic fin, more elongated dorsal fin and shorter anal fin, is associated with the PC3 - axis (e.g., some Stegastes, Chrysiptera, and Neophomacentrus species; Fig. 3C, PC3-).

The main axis of variation of the caudal peduncle (module 3) is elongation and degree of curvature. The first axis of variation shows that long caudal peduncles are more curved (e.g., Azurina; Fig. 4B, PC1-) than the short ones (e.g., some Abudefduf; Fig. 4A, PC1+). The second axis of variation shows that species with an elongated ventral edge present a less curved posterior edge (e.g., some Chromis species; Fig. 4A, PC2+), while species with a shorter ventral edge present a more curved posterior edge (e.g., Amphiprion; Fig. 4A, PC2+).

For the analyses of whole body shape, the first axis of variation showed that in elongated species where the eye and the snout are at a similar height, the pectoral fin is anterior to the pelvic fin and the dorsal fin origin. There is a general elongation of the cephalic region and caudal peduncle in a verti- cal axis, in relation to the trunk (e.g., Azurina and Lepidozygus; Fig. 5B, PC1+). The opposite characters, deep-bodied species, are associated with PC1axis (e.g., Dascyllus; Fig. 5A, PC1-). The PC2 showed a segregation among species with relatively elongated cephalic shape, less curved caudal peduncle, shorter anal and dorsal fins, and pectoral fins in a less horizontal angle of insertion (e.g., some Abudefduf, Chromis, and Azurina species; Fig. $5 \mathrm{~A}, \mathrm{~B}, \mathrm{PC} 2-)$. The PC2+ present the contrary characters, elongated anal and dorsal fin (e.g., Premnas and Pristotis; Fig. 5B, PC2+).

\section{Inter-Specific Allometry}

Results showed CS was a significant predictor of shape variation $(P<0.001)$, but only for a low percentage of shape variation. The trunk shape was most strongly correlated to size $\left(r^{2}=0.3 ; d f=38\right.$ $27740 ; F=350$ ), such that elongated trunks tend to be smaller than deep-trunks. A smaller proportion of shape variation was explained by size variation in the caudal peduncle $\left(r^{2}=-0.08 ; d f=12\right.$ $8760 ; F=61)$ and the cephalic region $\left(r^{2}=0.02\right.$; $d f=30-21900 ; F=12$ ). Larger caudal peduncles tend to be more curved than the smaller ones, and larger cephalic regions are generally more vertically elongated than smaller ones (Fig. 6).

\section{Test of Modular Configuration Defined A Priori}

The RV-coefficient value obtained for priori defined modules $(R V=0.57 ; P=0.01$; Supporting 


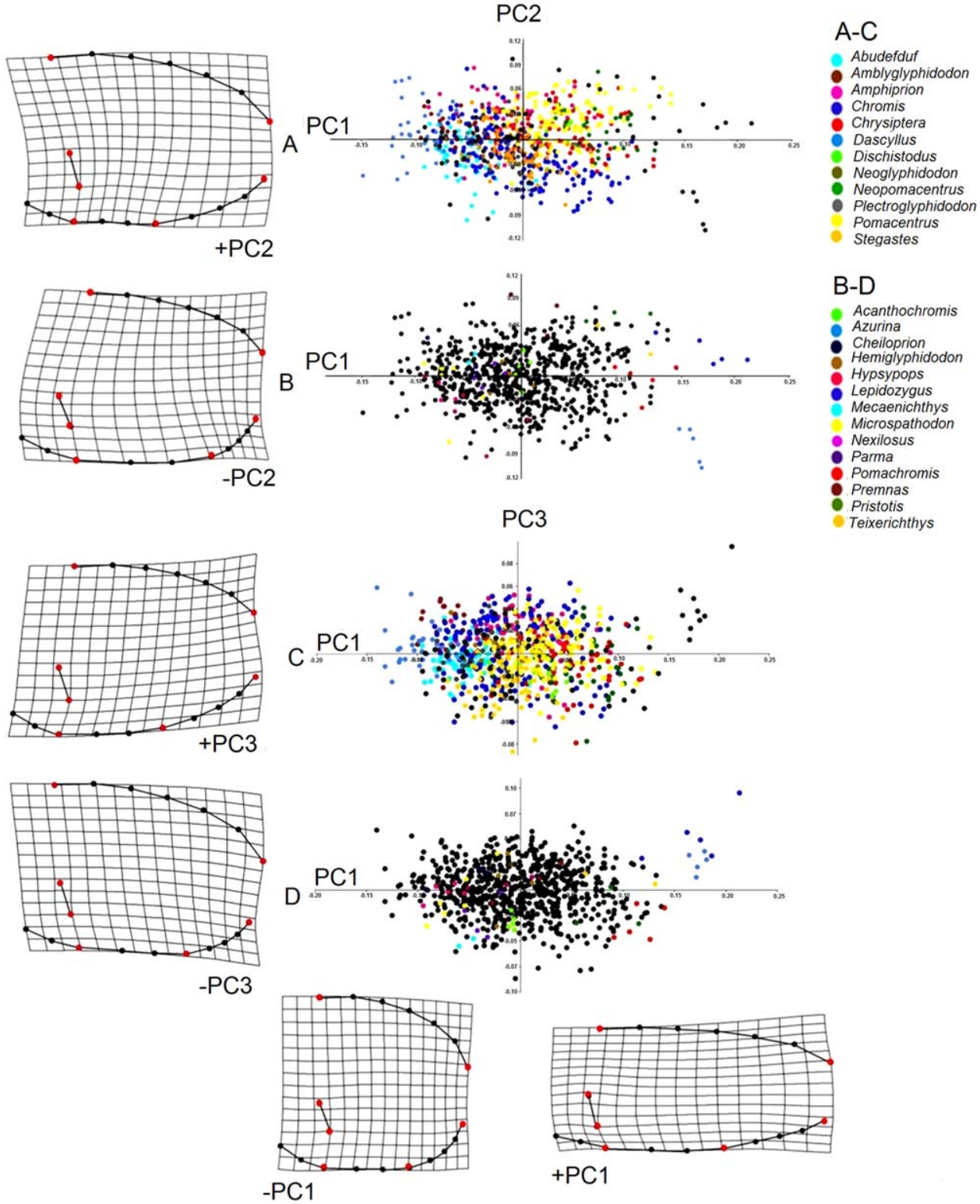

Fig. 3. Principal components analysis of the trunk. To highlight genera with few species the same graph is presented twice. Graph A includes all genera with more than five species while graph B only includes genera with less than five species. PC, principal component. Thin plate spline deformation grids represent the deformation of the most extreme specimen in each direction of the PC axes versus the grand mean. Red dots in the grids represent fin insertions.

Information 3) is lower that any randomly generated modules $(\mathrm{RV}=0.69-1)$ indicating that our priori defined modules are better option of modules segregation than any randomly generated possibility.

\section{Modular Evolution}

PGLS analysis revealed limited relationship among modules, supporting a modular evolution of the body parts (Table 1). In total, only 16 of 36 comparisons revealed a significant correlation between axis of variation in the three modules and phylogenetic relationship. Although each module is significantly related to at least one other module $(P \leq 0.05)$, the correlation values were always very low $\left(r^{2}\right.$ value $\leq 0.02$, Table 1$)$.

\section{Ecological Driving Forces}

Models of trait evolution showed strong support for the OU-model mainly in the second, third, and fourth axes of variation (PC2, 3, and 4; Table 2) across all modules and all ecological variables. Behavior and position in the water column are related to cephalic region and caudal peduncle in axes representing a high percentage of the total variation (behavior, module $1, \mathrm{PC} 2=23 \%$ and 


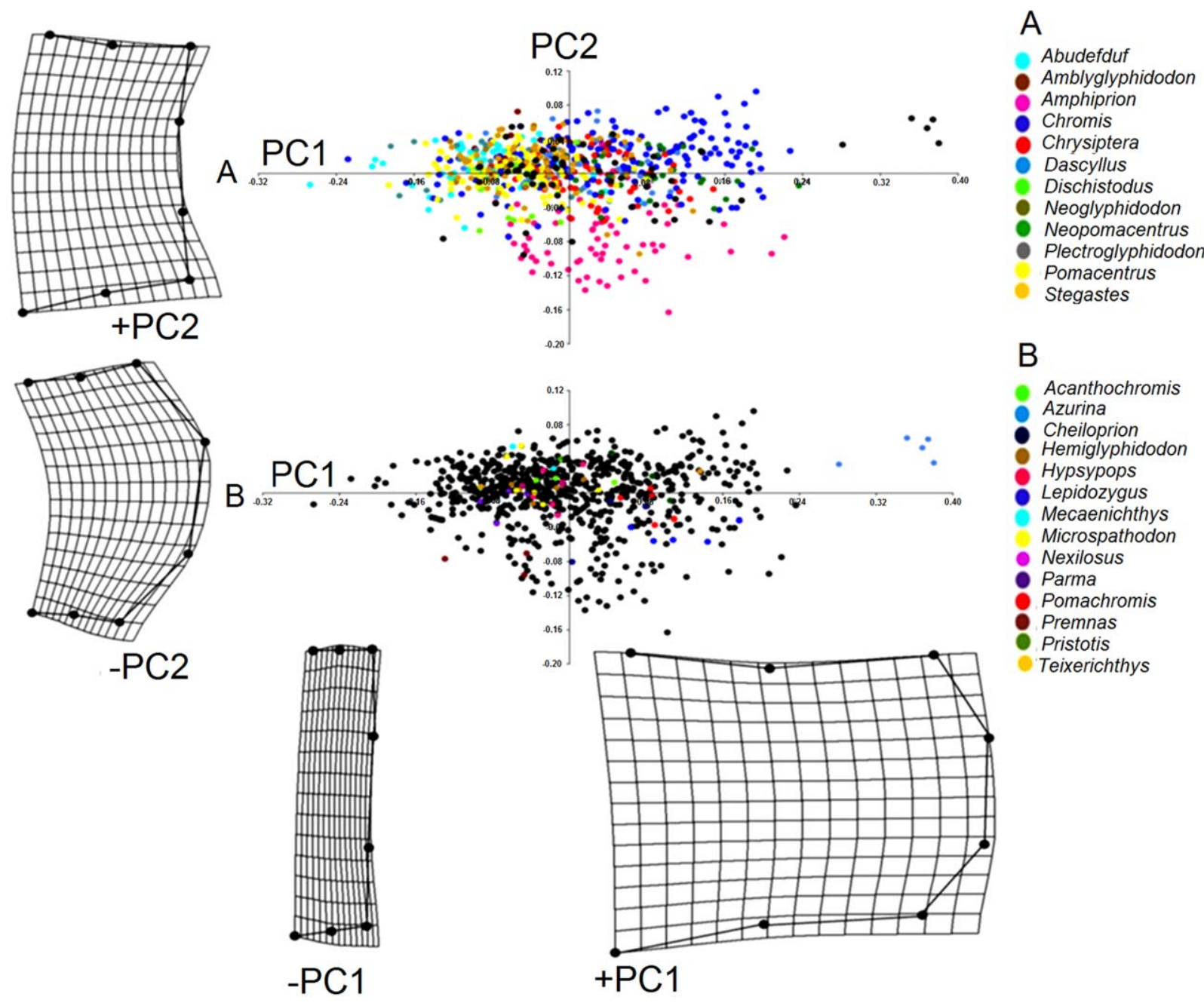

Fig. 4. Principal components analysis of the caudal peduncle. To highlight genera with few species the same graph is presented twice. Graph A includes all genera with more than five species while graph B only includes genera with less than five species. PC, principal component. Thin plate spline deformation grids represent the deformation of the most extreme specimen in each direction of the PC axes versus the grand mean.

module $3, \mathrm{PC} 2=13 \%$; position in the water column, module $1, \quad \mathrm{PC} 3=11 \%$ and module 3 , $\mathrm{PC} 2=13 \%)$. Conversely, wave exposure is related to all modules, in axes representing a lower percentage of the total variation (module 1, $\mathrm{PC} 3=11 \%$ and $\mathrm{PC} 4=7 \%$, module $2, \mathrm{PC} 3=10 \%$ and module $3, \mathrm{PC} 2=13 \%$; see the morphological variation related to each axis on Results; Main axes of morphological variation). Thus, our results clearly indicate that the ecological variables analyzed here influenced the shape of major anatomical modules during the evolutionary processes of the Pomacentridae family.

\section{DISCUSSION}

Although organisms are commonly viewed as integrated morphological units, they can also be viewed as a collection of semi-autonomous modules with unique positions and functions. Therefore, understanding the adaptation, evolution, and divergence within groups of organisms requires understanding how the underlying morphological and functional interactions act on these units (modules) and how changes in one unit may impact other units and functions across phylogenies (Zelditch and Carmichael, 1989; Marroig and Cheverud, 2001; Young and Hallgrímsson, 2005; Goswami, 2006a,b; Klingenberg, 2008; Singh et al., 2012).

By examining morphometric and ecological data from 204 species of damselfishes (including 27 of 29 genera) in a comparative phylogenetic framework, this study found evidence for modular evolution in the locomotor system of damselfishes. Specifically, results show that the modules of the damselfish locomotor system are constrained by behavior and habitat preferences. The integration of these modules produces internal constraints on the overall body morphology, resulting in distinctive morphologies. However, the integration among 


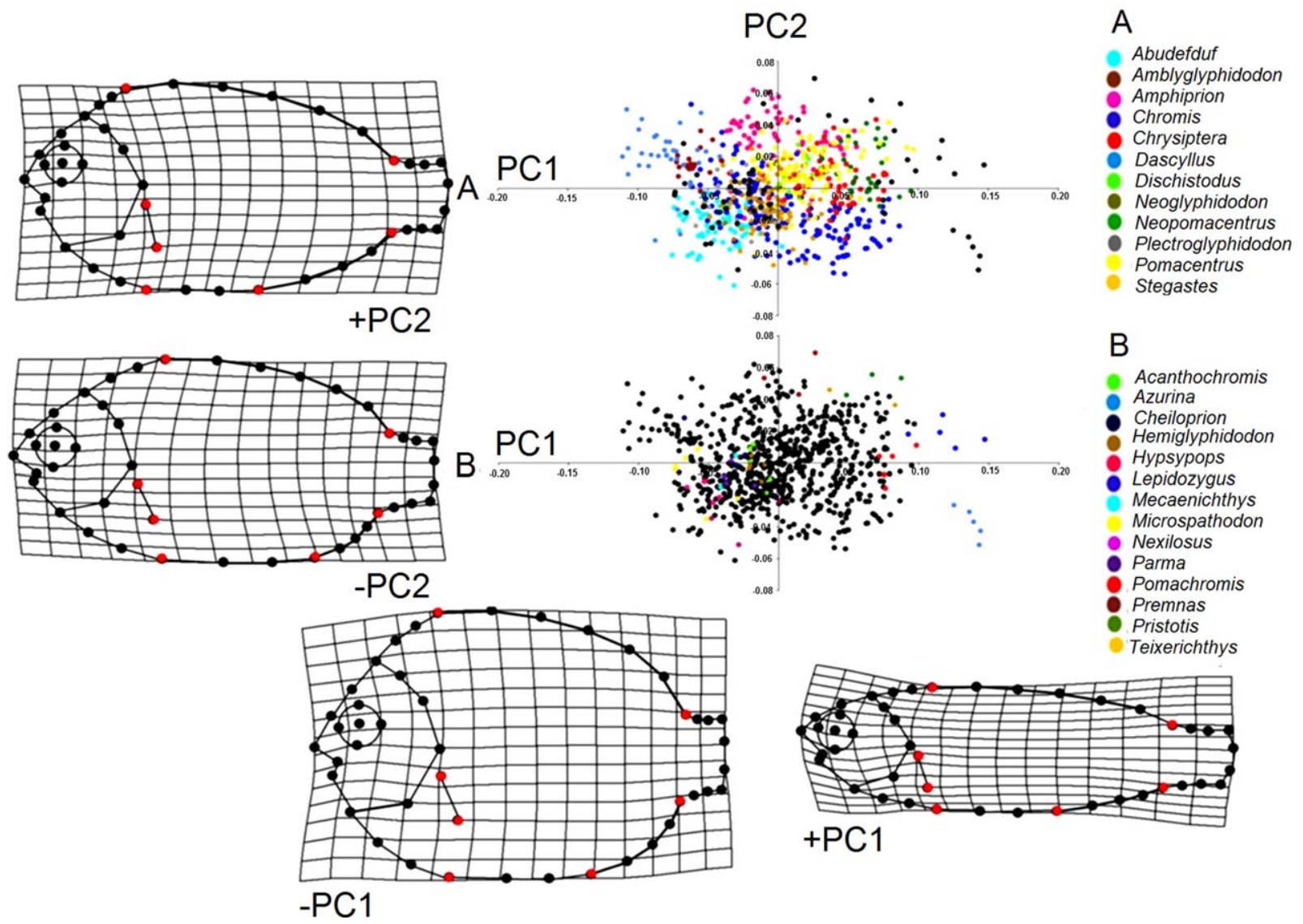

Fig. 5. Principal components analysis of the whole body. To highlight genera with few species the same graph is presented twice. Graph A includes all genera with more than five species while graph B only includes genera with less than five species. PC, principal component. Thin plate spline deformation grids represent the deformation of the most extreme specimen in each direction of the PC axes versus the grand mean. Red dots in the grids represent the fins.

locomotory modules is low (Table 1), potentially providing flexibility in generating morphological diversity that could contribute to species diversity.

\section{Modularity and Ecological Constraints on Locomotor System Shape of Damselfishes}

There are different ways to conceptualize morphological modules, including origins during development (Monteiro et al., 2005), integration among LMs with similar patterns of variation (Goswami, $2006 \mathrm{a}, \mathrm{b}$ ), and interactions of traits that perform one or more coordinated functions (Klingenberg, 2008). The latter "functional modality" definition (Mitteroecker and Bookstein, 2007) is more appropriate for characterizing the damselfish locomotory system because the cephalic region, trunk, and caudal peduncle collectively serve a common functional role, are integrated, and relatively independent from other modules.

Each module was described according to its own functions; however they all serve the same purpose, locomotion. For example, the trunk, dorsal, pelvic and anal fins are associated with stability and thrust (Harris, 1938; Drucker and Lauder, 2001, 2005; Fulton, 2007; Standen, 2008), while the caudal peduncle is associated with acceleration and thrust (Webb, 1982; Gibb et al., 1999), however, both trunk and caudal peduncle function together to increase and keep speeds during locomotion. Thus, even if our results show that anatomically nearby modules are more related among it, these results are related to share functions.

To our knowledge, only few studies have analyzed morphological modularity of fishes considering the whole body. Those analyses resulted in somewhat diverging results. Mabee et al. (2002) considered the anal and dorsal fins as a single module and the pelvic and pectoral fins separately. Larouche et al. (2015) just two modules in the whole body, the cephalic region as one module, and trunk-caudal peduncle, including all fins as the second module. Our results partially agreed with both suggestions. We found a strong relation among the caudal and dorsal region, and a relation among the pectoral and pelvic fins (Fig. 3). 


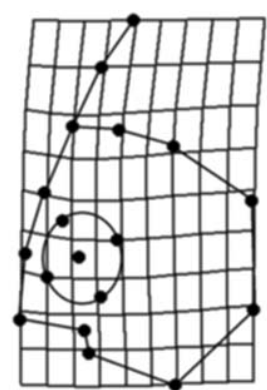

0.167

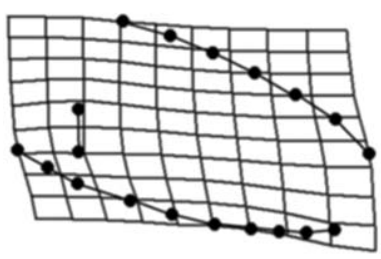

0.497

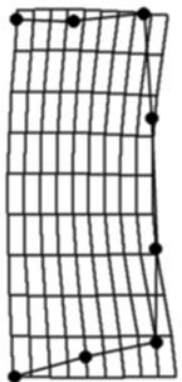

0.067

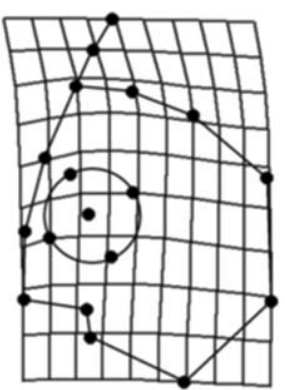

0.248
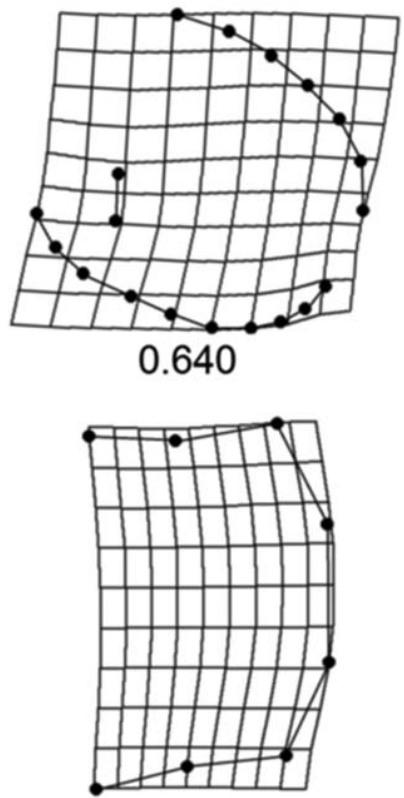

0.115
Fig. 6. Morphological variation related to size in the three modules of the locomotor system of damselfishes. Numbers represent the centroid size.

Also when we found a level of integration among the trunk and the caudal peduncle, our result still support the presence of three modules in the whole body.
The largest source of morphological variation observed in the damselfish locomotor system was related to the rostro-caudal elongation of the fish body, a major trend in shape diversity in reef fishes (Ward and Mehta, 2010; Aguilar-Medrano et al., 2011; Aguilar-Medrano, 2013; Claverie and Wainwright, 2014). Although, it is interesting to note that the three studied ecological variables do not show significant relationships with the first axis of variation but instead with the secondary axes. This might indicate that the rostro-caudal elongation of the body presents a strong phylogenetic signal in this fish group, while all secondary characters have being constrained by ecology.

Most elongated damselfish were largely schooling pelagic feeders, inhabiting the midwater column or close to the surface (Supporting Information 1). These species are generally small, and their elongated body tended to be associated with angular cephalic regions, creating a more streamlined profile that decreases drag and increases swimming speeds (Bushnell and Moore, 1991; Lighthill, 1993). This morphology was also associated with big eyes that are level with the snout, a common characteristic of predatory fishes that improves the efficiency of feeding (Griffin et al., 2001; Karplus and Algom, 1981). Lastly, elongated body forms were associated with an elongated caudal peduncle that is curved on the horizontal edge and posterior edge, creating a large area of thrust that promotes rapid acceleration (Webb, 1984; Webb and Weihs, 1986; Lauder, 2000). The combination of these morphological traits results in species that are fast and efficient swimmers, capable of rapid accelerations (e.g., Azurina and Lepidozygus), characteristics required to successfully exploit midwater habitats as well as those close to the surface.

In contrast, most deep-bodied damselfishes are territorial, benthic feeders, and inhabit environments close to the substratum (Frédérich et al., 2008; Cooper and Westneat, 2009; AguilarMedrano et al., 2011), and are larger than

TABLE 1. Results from phylogenetic generalized least squares analyses using a Brownian motion model for testing correlated evolution between morphological modules: Module 1, cephalic region; Module 2, trunk; and Module 3, caudal peduncle

\begin{tabular}{|c|c|c|c|c|c|c|c|c|c|}
\hline & & \multicolumn{4}{|c|}{ Cephalic region } & \multicolumn{3}{|c|}{ Trunk } & \multirow{2}{*}{$\frac{\text { Caudal peduncle }}{\text { PC1 }}$} \\
\hline & & PC1 & PC2 & PC3 & $\mathrm{PC} 4$ & PC1 & PC2 & PC3 & \\
\hline \multirow[t]{4}{*}{ Cephalic región } & PC1 & & & & & & & & \\
\hline & PC2 & $\mathrm{ns}$ & & & & & & & \\
\hline & PC3 & $\mathrm{ns}$ & $\mathrm{ns}$ & & & & & & \\
\hline & $\mathrm{PC} 4$ & $\mathrm{~ns}$ & $\mathrm{~ns}$ & $0.01^{*}$ & & & & & \\
\hline \multirow[t]{3}{*}{ Trunk } & PC1 & $0.02^{*}$ & $0.02 *$ & $0.02 *$ & $\mathrm{~ns}$ & & & & \\
\hline & PC2 & $-0.01^{*}$ & $-0.01^{*}$ & $-0.01^{*}$ & $\mathrm{~ns}$ & $-0.01^{*}$ & & & \\
\hline & PC3 & $\mathrm{ns}$ & $-0.02 *$ & $-0.02^{*}$ & $\mathrm{~ns}$ & $\mathrm{~ns}$ & $-0.02 *$ & & \\
\hline \multirow[t]{2}{*}{ Caudal peduncle } & PC1 & $-0.01^{*}$ & $-0.01^{*}$ & $-0.01^{*}$ & $\mathrm{~ns}$ & $-0.01^{*}$ & $-0.01 *$ & $\mathrm{~ns}$ & \\
\hline & PC2 & $\mathrm{ns}$ & $\mathrm{Ns}$ & $\mathrm{ns}$ & $\mathrm{ns}$ & $\mathrm{ns}$ & $\mathrm{ns}$ & $\mathrm{ns}$ & $\mathrm{ns}$ \\
\hline
\end{tabular}

Significant correlations are indicated by an asterisk, while ns indicate no significant results. PCs refer to each principal component. 
TABLE 2. Results of phylogenetic generalized least squares analyses testing correlated evolution between morphology and ecology

\begin{tabular}{|c|c|c|c|c|c|c|c|c|}
\hline & & & \multicolumn{2}{|c|}{ Wave exposure } & \multicolumn{2}{|c|}{$\begin{array}{l}\text { Position in the water } \\
\text { column }\end{array}$} & \multicolumn{2}{|c|}{ Behavior } \\
\hline & & & $\mathrm{AIC}$ & Corr. & $\mathrm{AIC}$ & Corr. & $\mathrm{AIC}$ & Corr. \\
\hline \multirow[t]{8}{*}{ Whole body } & PC1 & $\mathrm{BM}$ & -812.08 & $0.004 *$ & -806.45 & 0.000 & -809.17 & -0.001 \\
\hline & & OU & -687.34 & 0.003 & -686.84 & 0.003 & -690.27 & 0.009 \\
\hline & PC2 & BM & -831.40 & 0.000 & -846.50 & $0.005^{*}$ & -833.32 & 0.002 \\
\hline & & OU & -936.07 & $-0.006 *$ & -930.93 & 0.002 & -931.29 & -0.001 \\
\hline & PC3 & $\mathrm{BM}$ & -831.28 & 0.002 & -836.26 & $0.003^{*}$ & -831.96 & 0.002 \\
\hline & & OU & $-1,047.55$ & -0.001 & $-1,046.14$ & 0.000 & $-1,049.23$ & -0.003 \\
\hline & $\mathrm{PC} 4$ & $\mathrm{BM}$ & $-1,018.83$ & 0.000 & $-1,019.09$ & 0.001 & $-1,023.00$ & -0.005 \\
\hline & & $\mathrm{OU}$ & $-1,059.78$ & 0.003 & $-1,057.73$ & -0.002 & $-1,079.59$ & $-0.009 *$ \\
\hline \multirow[t]{8}{*}{ Module 1 Cephalic región } & PC1 & $\mathrm{BM}$ & -605.10 & $0.008 *$ & -606.13 & $0.006 *$ & -601.40 & 0.001 \\
\hline & & OU & -552.53 & 0.000 & -553.62 & 0.006 & -570.03 & $-0.029 *$ \\
\hline & $\mathrm{PC} 2$ & BM & -649.38 & 0.003 & -664.71 & $-0.008 *$ & -651.80 & 0.009 \\
\hline & & OU & -610.05 & -0.001 & -610.89 & -0.005 & -655.71 & 0.040* \\
\hline & PC3 & BM & -623.04 & $-0.012^{*}$ & -616.40 & $0.006^{*}$ & -611.70 & -0.002 \\
\hline & & OU & -800.40 & $-0.007 *$ & -804.24 & $0.007 *$ & -796.20 & -0.001 \\
\hline & PC4 & BM & -642.36 & -0.004 & -699.05 & $0.014^{*}$ & -643.41 & -0.006 \\
\hline & & $\mathrm{OU}$ & -794.05 & $-0.007 *$ & -788.80 & 0.000 & -790.81 & -0.004 \\
\hline \multirow[t]{6}{*}{ Module 2 trunk } & PC1 & $\mathrm{BM}$ & -726.34 & $-0.009 *$ & -712.94 & -0.001 & -715.48 & -0.002 \\
\hline & & OU & -599.56 & -0.005 & -598.19 & 0.002 & -603.65 & $-0.014^{*}$ \\
\hline & PC2 & $\mathrm{BM}$ & -774.47 & $0.005^{*}$ & -770.41 & -0.001 & -772.61 & -0.004 \\
\hline & & OU & -833.52 & 0.006 & -829.78 & 0.002 & -831.17 & -0.003 \\
\hline & PC3 & $\mathrm{BM}$ & -863.82 & 0.000 & -863.90 & 0.001 & -868.08 & -0.007 \\
\hline & & OU & -952.95 & $0.005 *$ & -947.45 & -0.001 & -950.08 & -0.003 \\
\hline \multirow[t]{4}{*}{ Module 3 Caudal peduncle } & PC1 & $\mathrm{BM}$ & -497.20 & 0.006 & -496.62 & 0.004 & -497.55 & 0.003 \\
\hline & & OU & -458.71 & -0.006 & -468.17 & $0.018^{*}$ & -458.81 & -0.005 \\
\hline & PC2 & $\mathrm{BM}$ & -636.52 & 0.005 & -636.36 & 0.004 & -635.89 & -0.001 \\
\hline & & OU & -790.93 & 0.009* & -793.38 & $-0.007 *$ & -799.06 & 0.015* \\
\hline
\end{tabular}

Two models were used, BM (Brownian motion) and OU (Ornstein-Uhlenbeck) and compared using Akaike information criterion scores (AIC). Corr.: correlation values. Bold values indicate the best fitted model. Asterisk indicated significant correlation $(P$ $=<0.05)$. Dashed circled values indicated significant correlation on BM as best fitted model and solid circled values indicated significant correlation on OU as best fitted model.

schooling damselfishes. Results showed that deepbodied species generally have deep cephalic profiles with lower positioned snouts that allow them to graze on algae, or prey on benthic invertebrates while maintaining visual awareness of predators (Bellwood et al., 2014). In addition, these species typically have short caudal peduncles that facilitate strong initial swimming bursts rather than sustained fast swimming required of midwater species. Furthermore, these species have deep-trunks that favor stability at slow swimming speeds, and are likely advantageous for negotiating structurally complex habitats (e.g., Dascyllus aruanus living in branching corals; Webb, 1982; Fulton, 2007).

Despite this generality, numerous taxa deviated from this pattern. For example Amphiprion presented a rounded cephalic profile, a trait commonly observed in benthic species, but its trunk and caudal peduncle were relatively long and similar to species living in the upper and mid-water column. In contrast, Hypsypops exhibited an angular cephalic profile, characteristic of species from the water column, but also had a high trunk and short caudal peduncle, traits generally associated with benthic habitats. Thus, while the evolution of pomacentrids is biased in specific phenotypic directions due to general rules that link the evolution of modules of the locomotor system (Klingenberg, 2005), these links are flexible. The low association among modules allows morphological diversity to increase by producing unexpected combinations. In turn, this variation may facilitate shifts into novel niche spaces, contributing to lineage diversification in pomacentrids.

Previous studies have demonstrated the relationship between cephalic shape and diet in damselfishes (Emery, 1973; Gluckmann and Vandewalle, 1998; Aguilar-Medrano et al., 2011; Frédérich et al., 2013). While the ecological variables studied in our analysis are highly related to locomotion, they also influence feeding behavior. For example, deepbodies species with short caudal peduncles were typically associated with slower, more maneuverable swimmers (Bartol et al., 2002; Fulton, 2007; Aguilar-Medrano, 2013). In turn, these characteristics were associated with being territorial and herbivorous (Frédérich et al., 2008; Cooper and Westneat, 2009; Aguilar-Medrano et al., 2011). Similarly, results showed that elongated species with longer caudal peduncles were associated with faster, more efficient swimming (Videler, 1993; Fulton, 2007; Aguilar-Medrano, 2013); these species were typically schooling and mostly zooplanktivorous (Frédérich et al., 2008; Cooper and Westneat, 
2009; Aguilar-Medrano et al., 2011). The strong connections observed between locomotion and feeding in damselfishes (see above) is similarly seen in other fishes, such as the Labridae (Collar et al., 2008) suggesting that constraints of swimming and feeding in an aquatic medium can have similar effects across distantly related taxa.

\section{Morphological Evolution of the Damselfish Locomotor System}

Our study system highlights the balance between evolvability and morphological constraints. Evolvability is the potential of populations to respond to natural selection and evolve (Wagner and Altenberg, 1996; Klingenberg, 2005; Singh et al., 2012) rising to novel phenotypes, while the morphological constraints imposed by integration of morphology within locomotor modules reduces the potential to vary within a population, conserving aspects across evolutionary time (Klingenberg, 2005; Singh et al., 2012).

Evolutionary analysis of damselfish morphology illuminates a limited range of morphological variation and a tendency to repeat shapes through clades (Cooper and Westneat, 2009; Frédérich et al., 2013). In particular, the integration among the cephalic region, trunk, and caudal peduncle suggest the action of morphological constraints because the integration of modules potentially limits the variation of each module (Martin et al., 2005). As such, evolutionary change is biased in specific phenotypic directions (Klingenberg, 2005), potentially slowing the rate of evolution and/or constraining morphological evolution to a smaller range of possible variation (Goswami and Polly, 2010b). Thus, the integration among modules may explain the limited range of morphological variation in pomacentrids (giving this group their distinctive shape) and the tendency to reiterate patterns throughout the evolutionary history of this group.

While results suggest integration among modules, a high percentage of the morphological variation within damselfishes shows little integration. The freedom to evolve more independently from the main body pattern may result in greater morphological variation and species diversity in some lineages of pomacentrids. For example, a higher level of modularity has probably operated for the evolution of Amphiprion. This genus combines rounded cephalic profile with elongated trunk and caudal peduncle, and this atypical combination of shapes may be considered as a novelty in damselfishes. In addition to physiological adaptations, this modular novelty could be related to the colonization of untapped niches such as sea anemones and could explain the high rate of diversification observed in the clade of clownfishes (Litsios et al., 2012). Such "independent" characters are likely critical for evolvability by increasing the potential for morphological variation (Goswami and Polly, 2010b).
As expected, behavior and habitat preferences impact the morphological variation of each module of the fish body during the evolution. Thus, selection pressure and integration of damselfish locomotory modules should result in a relatively low number of morphological possibilities and correspondingly limited morphological diversity. However, evolution has produced lineages of damselfish that do not seem to follow these constraints. Hence the results suggest that the evolutionary success of Pomacentridae may lie in the delicately balanced interaction between integrated parts of the morphology that produce a functional body design and weakly integrated or relatively independent morphological aspects that facilitate adaptation and diversification.

\section{ACKNOWLEDGMENTS}

Consejo Nacional de Ciencia y Tecnología (CONACYT), Mexico and University of California, Institute for Mexico and the United States (UC MEXUS), USA funded the Postdoctoral research of R. Aguilar-Medrano. B. Frédérich is a Postdoctoral researcher of the F.R.S.-FNRS (Belgium).

\section{CONFLICT OF INTEREST}

The authors declare that they have no conflict of interest.

\section{ETHICAL APPROVAL}

None of the organisms used in this analysis were collected in the field. Most photographs were obtained from accessioned museum specimens, with additional photographs obtained from online resources such as MorphBank (www.morphbank. net), FishBase (Froese and Pauly 2014), and John E. Randall's Fish Photos (pbs.bishopmuseum.org/ images/JER).

\section{LITERATURE CITED}

Adams DC, Otarola-Castillo E, Sherratt E. 2014. geomorph: Software for geometric morphometric analyses. $\mathrm{R}$ package version 2.0. http://cran.r-project.org/web/packages/geomorph/ index.html.

Aguilar-Medrano R. 2013. Body shape evolution of Chromis and Azurina species (Percifomes, Pomacentridae) of the eastern Pacific. An Biol 63:217-232.

Aguilar-Medrano R, Frédérich B, De Luna E, Balart EF. 2011. Patterns of morphological evolution of the cephalic region in damselfishes (Perciformes: Pomacentridae) of the eastern Pacific. Biol J Linn Soc 102:593-613.

Aguilar-Medrano R, Frédérich B, Balart EF, De Luna E. 2013. Diversification of the pectoral fin shape in damselfishes (Perciformes, Pomacentridae) of the Eastern Pacific. Zoomorphology 132:197-213.

Akaike H. 1973. Information theory and an extension of the maximum likelihood principle. In: Petrov BN, Csaki F, editors. Second International Symposium on Information Theory. Budapest: Akademi Kiado. pp 267-281. 
Allen GR. 1991. Damselfishes of the World. Melle, Germany: Mergus Press. p 271.

Bartol IK, Gordon AM, Gharib M, Hove JR, Webb P, Weihs D. 2002. Flow patterns around the carapaces of rigid-bodied, multipropulsor boxfish (Teleostei: Ostraciidae). Integr Comp Biol 42:971-980.

Beaulieu JM, Jhwueng DC, Boettiger C, O'Meara BC. 2012. Modeling stabilizing selection: Expanding the OrnsteinUhlenbeck model of adaptive evolution. Evolution 66:2369 2383.

Bellwood DR. 1996. The Eocene fishes of Monte Bolca: The earliest coral reef fish assemblage. Coral Reefs 15:11-19.

Bellwood DR, Sorbini L. 1996. A review of the fossil record of the Pomacentridae (Teleostei: Labroidei) with a description of a new genus and species from the Eocene of Monte Bolca, Italy. Zool J Linn Soc 117:159-174.

Bellwood DR, Goatley CHR, Brandl SJ, Bellwood O. 2014. Fifty million years of herbivory on coral reefs: Fossils, fish and functional innovations. Proce Roy Soc B 281:20133046.

Blake RW. 2004. Fish functional design and swimming performance. J Fish Biol 65:1193-1222.

Boisclair D, Sirois P. 1993. Testing assumptions of fish bioenergetics models by direct estimation of growth, consumption, and activity rates. T Am Fish Soc 122:784-796.

Bookstein FL. 1991. Morphometric Tools for Landmark Data Geometry and Biology. Cambridge: University Press. p 466.

Bushnell DM, Moore KJ. 1991. Drag reduction in nature. Annu Rev Fluid Mech 23:65-79.

Butler MA, King AA. 2004. Phylogenetic comparative analysis: A modeling approach for adaptive evolution. Am Nat 164 683-695.

Cangelosi R, Goriely A. 2007. Component retention in principal component analysis with application to cDNA microarray data. Biology Direct 2:2. doi: 10.1186/1745-6150-2-2.

Claverie T, Wainwright PC. 2014. A morphospace for reef fishes: Elongation is the dominant axis of body shape evolution. PLoS One 9:e112732.

Collar DC, Wainwright PC, Alfaro ME. 2008. Integrated diversification of locomotion and feeding in labrid fishes. Biol Lett 4:84-86.

Cooper WJ, Westneat MW. 2009. Form and function of damselfish skulls: rapid and repeated evolution into a limited number of trophic niches. BMC Evol Biol 9:24.

Davis JC. 1986. Statistics and Data Analysis in Geology. New York: John Wiley \& Sons. p 646.

Drucker EG, Lauder GV. 2001. Locomotor function of the dorsal fin in teleost fishes: Experimental analysis of wake forces in sunfish. J Exp Biol 204:2943-2958.

Drucker EG, Lauder GV. 2005. Locomotor function of the dorsal fin in rainbow trout: Kinematic patterns and hydrodynamic forces. J Exp Biol 208:4479-4494.

Emery AR. 1973. Comparative ecology and functional osteology of fourteen species of damselfish (Pisces: Pomacentridae) at Alligator Reef, Florida Keys. B Mar Sci 23:649-770.

Eschmeyer WN. 2014. Catalog of fishes: Genera, species, references. Available at: http://research.calacademy.org/researchichthyology/catalog. Accessed September 2015.

Frédérich B, Pilet A, Parmentier E, Vandewalle P. 2008. Comparative trophic morphology in eight species of damselfishes (Pomacentridae). J Morph 269:175-188.

Frédérich B, Sorenson L, Santini F, Slater GJ, Alfaro ME. 2013. Iterative ecological radiation and convergence during the evolutionary history of damselfishes (Pomacentridae). Am Nat 181:94-113.

Froese R, Pauly D. 2014. FishBase: Concepts, design and data sources. ICLARM, Los Baños, Laguna. Available at: http:// www.fishbase.org. Accessed January 2015.

Fulton CJ. 2007. Swimming speed performance in coral reef fishes: Field validations reveal distinct functional groups. Coral Reefs 26:217-228.

Fulton CJ. 2010. The role of swimming in reef fish ecology. In: Domenici P, Kapoor BG, editors. Fish Swimming: An Etho-
Ecological Perspective. Chapter 12. Enfield: Science Publishers. pp 374-406.

Fulton CJ, Bellwood DR, Wainwright PC. 2005. Wave energy and swimming performance shape coral reef fish assemblages. Proc Roy Soc Lond B 272:827-832.

Gibb A, Jayne BC, Lauder GV. 1994. Kinematics of pectoral fin locomotion in the bluegill sunfish Lepomis macrochirus. J Exp Biol 189:133-161.

Gibb AC, Dickson KA, Lauder GV. 1999. Tail kinematics of the chub mackerel Scomber japonicus: Testing the homocercal tail model of fish propulsion. J Exp Biol 202:2433-2447.

Gluckmann I, Vandewalle P. 1998. Morphofunctional analysis of the feeding apparatus in four Pomacentridae species: Dascyllus aruanus, Chromis retrofasciata, Chrysiptera biocellata and C. unimaculata. Ital J Zool 65:421-424.

Goswami A. 2006a. Cranial modularity shifts during mammalian evolution. Am Nat 168:270-280.

Goswami A. 2006b. Morphological integration in the carnivoran skull. Evolution 60:169-183.

Goswami A, Polly PD. 2010a. Methods for studding morphological integration and modularity. In: Alroy J, Hunt G, editors. Quantitative Methods in Paleobiology, Vol. 16. Ithaca, NY: The Paleontological Society Papers. pp 213-243.

Goswami A, Polly PD. 2010b. The influence of modularity on cranial morphological disparity in Carnivora and Primates (Mammalia). Plos One 5:e9517.

Griffin AS, Evans CS, Blumstein DT. 2001. Learning specificity in acquired predator recognition. An Behav 62:577-589.

Harmon L, Schulte J, Larson A, Losos J. 2003. Tempo and mode of evolutionary radiation in iguanian lizards. Science 301:961-964.

Harmon L, Weir J, Brock C, Glor R, Challenger W. 2008. GIEGER: Investigating evolutionary radiations. Bioinformatics 24:129-131.

Harris JE. 1938. The role of the fins in the equilibrium of the swimming fish. II. The role of the pelvic fins. J Exp Biol 1938:32-47.

Hertz PE, Huey RB, Garland T Jr. 1988. Time budgets, thermoregulation, and maximal locomotor performance: Are ectotherms olympians or boy scouts? Am Zool 28:927-938. -

Higham TE. 2007. Feeding, fins and braking maneuvers: Locomotion during prey capture in centrarchid fishes. J Exp Biol 210:107-117.

Huey RB, Stevenson RD. 1979. Integrating thermal physiology and ecology of ectotherms: A discussion of approaches. Am Zool 19:357-366.

Karplus I, Algom D. 1981. Visual cues for predator face recognition by reef fishes. Z Tierpsychol 55:343-364.

Klingenberg CP. 2005. Developmental constraints, modules and evolvability. In: Hallgrımsson B, Hall BK, editors. Variation: A Central Concept in Biology. Burlington, MA: Elsevier. pp 219-247.

Klingenberg CP. 2008. Morphological integration and developmental modularity. Ann Rev Ecol Evol Syst 39:115-132.

Klingenberg CP. 2009. Morphometric integration and modularity in configurations of landmarks: Tools for evaluating a priori hypotheses. Evol Develop 11:405-421.

Koch F, Wieser Q. 1983. Partitioning of energy in fish: Can reduction of swimming activity compensate for the cost of production. J Exp Biol 107:141-146.

Larouche O, Cloutier R, Zelditch ML. 2015. Head, body and fins: Patterns of morphological integration and modularity in fishes. Evol Biol 42;3:296-311. doi: 10.1007/s11692-015-9324-9.

Lauder GV. 2000. Function of the caudal fin during locomotion in fishes: Kinematics, flow visualization, and evolutionary patterns. Am Zool 40:101-122.

Lighthill J. 1993. Estimates of pressure differences across the head of a swimming clupeid fish. Philos T Roy Soc B 341: $129-140$.

Litsios G, Pellissier L, Forest F, Lexer C, Pearman PB, Zimmermann NE, Salamin N. 2012. Trophic specialization influences the rate of environmental niche evolution in damselfishes (Pomacentridae). Proc R Soc B 279:3662-3669. 
Mabee PM, Crotwell PL, Bird NC, Burke AC. 2002. Evolution of median fin modules in the axial skeleton of fishes. J Exp Zool 294:77-90.

Marroig G, Cheverud JM. 2001. A comparison of phenotypic variation and covariation patterns and the role of phylogeny, ecology, and ontogeny during cranial evolution of New World monkeys. Evolution 55:2576e2600.

Martin DP, van der Walt E, Posada D, Rybicki EP. 2005. The evolutionary value of recombination is constrained by genome modularity. PLoS Genet 1:e51.

Mitteroecker P, Bookstein F. 2007. The evolutionary role of modularity and integration in the hominoid cranium. Evolution 62:943-958.

Monteiro LR. 1999. Multivariate regression models and geometric morphometrics: The search for causal factors in the analysis of shape. Syst Biol 48:192-199.

Monteiro LR, Bonato V, dos Reis SF. 2005. Evolutionary integration and morphological diversification in complex morphological structures: Mandible shape divergence in spiny rats (Rodentia, Echimyidae). Evol Dev 7:429-439.

Orme D, Freckleton RP, Thomas G, Petzoldt T, Fritz SA. 2011. Caper: Comparative analyses of phylogenetics and evolution in R. http://r-forge.rproject.org/projects/caper.

Paradis E, Claude J, Strimmer K. 2004. APE: Analyses of phylogenetics and evolution in $\mathrm{R}$ language. Bioinformatics 20 : 289-290.

Pinheiro J, Bates D, DebRoy S, Sarkar D, R Core Team. 2014. nlme: Linear and nonlinear mixed effects models. $\mathrm{R}$ package version 3.1-117, http://CRAN.R-project.org.

Plaut I. 2001. Critical swimming speed: its ecological relevance. Compar Biochem Physiol A 131:41-50. -

Rice AN, Westneat MW. 2006. Coordination of feeding, locomotor and visual systems in parrotfishes (Teleostei: Labridae). J Exp Biol 208:3503-3518.

Rohlf FJ. 1993. Relative warps analysis and an example of its application to mosquito wings. In: Marcus LF, Bello E, Garcia-Valdecasas A, editors. Contributions to Morphometrics. Madrid: Monografías del Museo Nacional de Ciencias Naturales, CSIC. pp 139-151.

Rohlf FJ. 1999. Shape statistics: Procrustes superimpositions and tangent spaces. J Classif 16:197-223.

Rohlf FJ. 2014. Suny stonny brook. http://life.bio.sunysb.edu/ $\mathrm{morph} /$.
Rohlf FJ, Marcus LF. 1993. A revolution in morphometrics. Trends Ecol E 8:129-132.

Rohlf FJ, Slice D. 1990. Extension of the procrustes method for the optimal superposition of landmarks. Syst Zool 39:40-59.

Simon HA. 1962. The architecture of complexity. Proc Am Philos Soc 106:467-482.

Singh N, Harvati K, Hublin J, Klingenberg CP. 2012. Morphological evolution through integration: A quantitative study of cranial integration in Homo, Pan, Gorilla and Pongo. J Hum E $62: 155 \mathrm{e} 164$.

Standen EM. 2008. Pelvic fin locomotor function in fishes: Three-dimensional kinematics in rainbow trout (Oncorhynchus mykiss). J Exp Biol 211:2931-2942.

Videler JJ. 1993. Fish Swimming. London, UK: Chapman and Hall/Springer. p 260.

Wagner GP. 1995. Adaptation and the modular design of organisms. Lec Notes Artif Int 929:317-328.

Wagner GP, Altenberg L. 1996. Complex adaptations and the evolution of "evolvability". Evolution 50:967-976.

Wainwright PC, Bellwood DR, Westneat MW. 2002. Ecomorphology of locomotion in labrid fishes. Environ Biol Fish 65:47-62.

Ward AB, Mehta RS. 2010. Axial elongation in fishes: using morphological approaches to elucidate developmental mechanisms in studying body shape. Integr Comp Biol 50:1106-1119.

Webb PW. 1982. Locomotor patterns in the evolution of Actinopterygians fishes. Am Zool 22:329-342.

Webb PW. 1984. Body form, locomotion and foraging in aquatic vertebrates. Am Zool 24:107-120.

Webb PW. 1994. The biology of fish swimming. In: Maddock L, Bone Q, Rayner JMV, editors. Mechanics and Physiology of Animal Swimming. Cambridge: Cambridge University Press. pp 45-62.

Webb PW, Weihs D. 1986. Functional locomotor morphology of early life history stages of fishes. T Am Fish Soc 115:115-127.

Young NM, Hallgrímsson B. 2005. Serial homology and the evolution of mammalian limb covariation structure. Evolution 59:2691-2704.

Zelditch ML, Carmichael AC. 1989. Ontogenetic variation in patterns of developmental and functional integration in skulls of Sigmodon fulviventer. Evolution 43:814-824.

Zelditch ML, Swiderski DL, Sheets HD, Fink WL. 2004. Geometric morphometrics for biologists: A primer. London: Elsevier Academic Press. p 443. 